\title{
Anxiety and depression correlate with disease and quality-of-life parameters in Chinese patients with ankylosing spondylitis
}

This article was published in the following Dove Press journal:

Patient Preference and Adherence

20 May 2016

Number of times this article has been viewed

\section{Xujuan $\mathrm{Xu}^{1, *}$ \\ Biyu Shen ${ }^{2,3, *}$ \\ Aixian Zhang ${ }^{4}$ \\ Jingwei $\mathrm{Liu}^{3}$ \\ Zhanyun $\mathrm{Da}^{4}$ \\ Hong $\mathrm{Liu}^{4}$ \\ Zhifeng $\mathrm{Gu}^{4}$}

'Department of Nursing, Affiliated Hospital of Nantong University,

${ }^{2}$ School of Nursing, Nantong University, ${ }^{3}$ Department of Nursing,

The Second Affiliated Hospital of Nantong University, ${ }^{4}$ Department of Rheumatology, Affiliated Hospital of Nantong University, Nantong, People's Republic of China

*These authors contributed equally to this work

\begin{abstract}
Aim: To evaluate the relationship between mental and physical health in Chinese patients with ankylosing spondylitis (AS) and to identify the predictors of psychological status.

Methods: Patients with AS ( $\mathrm{n}=103)$ and healthy controls $(\mathrm{n}=121)$ were surveyed between 2010 and 2011 (cross-sectional study). The Bath Ankylosing Spondylitis Disease Activity Index, Bath Ankylosing Spondylitis Functional Index, Bath Ankylosing Spondylitis Metrology Index, pain visual analog scale, Health Assessment Questionnaire, revised Self-Rating Anxiety Scale, revised Self-Rating Depression Scale, and Short-Form 36 questionnaire were administered.

Results: The frequency of anxiety and depression in patients with AS was higher than that in healthy controls $(P<0.001)$. Severe disease status and reduced quality of life $(\mathrm{QoL})$ were associated with anxiety and depression. Disease activity and somatic pain were more severe in the anxious and depressed subgroups. Impaired physical functioning (assessed by Bath Ankylosing Spondylitis Functional Index) was higher in the anxious and depressed subgroups, while measures of spinal mobility (assessed by Bath Ankylosing Spondylitis Metrology Index) were not associated with depression. Lower QoL was observed in the depressed subgroup.

Conclusion: Low socioeconomic status, lack of health insurance, and fatigue contributed to depression in Chinese patients with AS. These patients may require a psychological care approach that is different from those of other countries.
\end{abstract}

Keywords: ankylosing spondylitis, disease activity, psychological status, quality of life

\section{Introduction}

Ankylosing spondylitis (AS) is a common inflammatory rheumatic disorder characterized by axial and/or peripheral arthritis associated with enthesitis (inflammation of the entheses, ie, the sites where the tendons insert into bones), dactylitis (inflammation of an entire digit), and potential extra-articular manifestations such as uveitis (inflammation of the iris, ciliary body, and choroid) and rash. ${ }^{1-3}$ This condition is more commonly diagnosed in men. ${ }^{1-3}$ AS may promote inflammation and pain in the entheses, joints, and spine, gradually leading to reduced spinal mobility, stiffness, fatigue, sleep disturbances, and psychological consequences, including depression, anxiety, and stress. ${ }^{4-6}$

Compared to healthy individuals, patients with rheumatic diseases are more likely to be depressed. Studies in Europe and the US were the first to demonstrate that psychological distress (characterized by depressive and anxious symptoms) is common in patients with chronic musculoskeletal pain. ${ }^{7-9}$ In the UK, impaired quality of life (QoL) and functional disability were found to be among the most powerful predictors of mood disturbances. ${ }^{1}$ It was reported that patients with AS are prone to anxiety or depression in Turkey and have a deteriorated QoL in Tunisia. ${ }^{3}$ Additionally, impaired
Correspondence: Zhifeng Gu

Department of Rheumatology, Affiliated Hospital of Nantong University, 20 Xisi Road, Nantong 22600I, People's Republic of China

Tel/fax +86513 8II685I2

Email guzhifeng@।26.com (c) 92016 Xu et al. This work is published and licensed by Dove Medical Press Limited. The full terms of this license are available at https://www.dovepress.com/terms.php
and incorporate the Creative Commons Attribution - Non Commercial (unported, v3.0) License (http://creativecommons.org/licenses/by-nc/3.0/). By accessing the work you

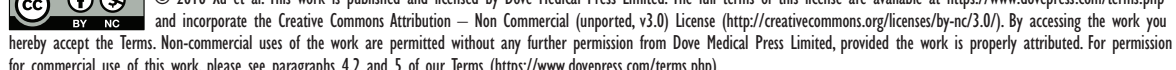


QoL and functional disability have been found to be the independent risk factors of psychological disorders in general. ${ }^{10}$

Despite an incidence of mental illness that is equivalent to other countries, ${ }^{10}$ cultural characteristics of the Chinese people are responsible for differences in coping with stressful or bad events. ${ }^{11-13}$ In addition, a specific subtype of the $H L A$ $B 27$ gene, which is responsible for AS, has been reported in Chinese patients only. In addition, changes in the HLA gene family have been reported to be associated with mood disorders. ${ }^{14}$

Therefore, the primary objective of this study was to evaluate the relationship between disease activity and psychological status in Chinese patients with AS. The secondary objective was to identify the predictors of psychological status. This is the first study to assess correlations among the psychological status, disease parameters, and QoL in Chinese patients with AS.

\section{Patients and methods}

\section{Participants}

This study was approved by the Ethics Committee of the Affiliated Hospital of Nantong University. All patients and controls provided written informed consent. Patients with AS were recruited from the Affiliated Hospital of Nantong University between January 2010 and July 2011. Patients with AS were included if they met the modified New York criteria for AS. ${ }^{6}$ Exclusion criteria were 1) comorbidity (cardiac, respiratory, gastrointestinal, neurological, endocrine, etc); 2) infection influencing AS activity or their functional or psychological status; 3) history of anxiety or depression prior to AS onset; or 4) incomplete questionnaires. A total of 112 patients with AS and 127 healthy individuals were invited to participate in the study. Controls were randomly selected from individuals who underwent a health examination at the Affiliated Hospital of Nantong University between January 2010 and July 2011. Patients and controls were frequency matched by age and sex. Controls with severe systemic diseases or psychiatric disorders were not recruited.

Questionnaires and other assessments were administered to participants between January 2010 and July 2011. All participants completed written questionnaires under physician supervision in a clinical setting. The Bath Ankylosing Spondylitis Disease Activity Index (BASDAI) and Bath Ankylosing Spondylitis Functional Index (BASFI) assessment tools were self-completed during a visit at the clinic. The Bath Ankylosing Spondylitis Metrology Index
(BASMI) was evaluated by the same two clinicians for all patients; discrepancies were solved by discussion.

\section{Assessment tools}

The BASDAI was used to measure disease activity. ${ }^{5}$ This scale quantitatively and qualitatively assesses fatigue, spinal pain, peripheral arthritis, enthesitis, and morning stiffness during the week prior to the survey using visual analog scales (VASs). Lower BASDAI scores indicate less active disease. This test has been validated in a Chinese population. $^{15}$

The BASFI was used to assess functioning during the month prior to the survey using VASs. Higher scores indicate impaired function. This test has been validated in a Chinese population. ${ }^{15}$

The BASMI was used to grade spine and hip mobility by measuring the distance from the tragus to the wall, lumbar flexion, cervical rotation, lumbar side flexion, and maximal intermalleolar distance. ${ }^{8}$ This test has been validated in a Chinese population. ${ }^{15}$

The VAS pain measure assesses general pain using a VAS. We used a $10 \mathrm{~cm}$ VAS where the patients had to indicate their level of pain on the line.

The Health Assessment Questionnaire (HAQ) was administered to quantify the degree of difficulty in performing tasks in ten functional areas. ${ }^{7}$ Two subscales were added to the original HAQ and were each composed of five items focusing on specific aspects of activities that would be difficult for persons with impaired spinal mobility.

The revised Self-Rating Anxiety Scale (SAS) was used to evaluate the level of anxiety symptoms during the week prior to the survey. ${ }^{9}$ Scores $>50$ indicate anxious symptoms.

The revised Self-Rating Depression Scale (SDS) was used to assess mood symptoms during the week prior to the survey (eg, "I feel downhearted, blue, and sad."). ${ }^{16}$ Scores $>53$ indicate depressive symptoms.

\section{Quality of life}

General health status was measured using the Short-Form 36 (SF-36) questionnaire to assess physical functioning, role limitations due to physical problems and emotional problems, social functioning (SF), mental health, energy/vitality, body pain, and general health perception. ${ }^{17}$ High scores denote better health.

\section{Laboratory tests}

Erythrocyte sedimentation rate (ESR) and C-reactive protein (CRP) levels were measured in patients with AS. The normal 
range for ESR was $0-15 \mathrm{~mm} / \mathrm{h}$ (male) or 0-20 $\mathrm{mm} / \mathrm{h}$ (female) and was $0-8 \mathrm{mg} / \mathrm{L}$ for CRP.

\section{Statistical analysis}

Data are expressed as mean \pm standard deviation (SD) for continuous variables and as frequencies (\%) for categorical variables. SPSS 10.0 (SPSS Inc., Chicago, IL, USA) was used for data management and analysis. Descriptive analyses were used to present participant characteristics. Student's $t$-tests were used for continuous variables, chi-square tests were used for categorical variables, and Pearson's correlation analysis was used to assess correlations between parametric variables. Stepwise regression analyses were conducted for SAS and SDS scores to explore significant predictors' anxiety and depression. $P<0.05$ was considered statistically significant.

\section{Results}

\section{Sample characteristics}

Table 1 lists the subjects' demographics, medical, psychological, and QoL variables. From the total of 112 patients with AS and 127 healthy individuals, nine patients with AS and six healthy controls did not complete the questionnaires; therefore, 103 patients with AS (78 males and 25 females) and 121 healthy controls (73 males and 48 females) were included in this cross-sectional study. There were no significant differences between the two groups in terms of age and sex. As expected, scores from the SAS and SDS were significantly higher in the AS group when compared with that of the control group. Among the 103 patients with AS, $19(18.4 \%)$ and $38(36.9 \%)$ patients were at high risk for anxiety and depression, respectively. These values were significantly higher when compared with those of the control group (8 [6.6\%] and 16 [13.2\%] for anxiety and depression, respectively, $P<0.001)$. Twenty-four (23.3\%) patients with AS had elevated ESR, and 41 (39.8\%) had increased CRP levels. Scores for AS disease measurements were BASDAI: 2.9 \pm 2.4 , BASFI: 0.9 \pm 1.5 , BASMI: $2.4 \pm 1.8$, Health Assessment Questionnaire: 2.8 \pm 2.2 , and VAS pain: $2.2 \pm 4.1$.

\section{Disease status and QoL association with anxiety and depression}

In this study, scores of BASDAI, VAS pain, and all SF-36 domains (except SF) were correlated with the scores of the SAS and SDS $(P<0.05)$. The SF scores correlated with SDS scores, while the Health Assessment Questionnaire scores correlated with SAS scores $(P<0.05)$. BASFI, BASMI, ESR, and CRP levels did not correlate with the SAS or SDS scores (Table 2).

\section{Disease status and QoL in the anxious and depressed subgroups}

There were significant differences in the BASDAI and VAS pain scores between the anxious (SAS scores $\geq 50$ ) and nonanxious subgroups (SAS scores $<50$ ). There was no difference in the SF-36 domains between the two subgroups, but in the depressed subgroup, the BASDAI, BASFI, and VAS pain scores were significantly higher when compared with those of the nondepressed subgroup. In addition, all SF-36 domains except body pain, general health perception, and SF were significantly lower in the depressed subgroup (Table 3).

Table I Demographics, psychological and disease characteristics in patients with AS and controls

\begin{tabular}{|c|c|c|c|}
\hline Variables & AS $(n=103)$ & Controls $(n=121)$ & $P$-value \\
\hline Male $^{a}$ & $78(75.7 \%)$ & $73(60.3 \%)$ & 0.62 \\
\hline Age, years ${ }^{b}$ & $32.9 \pm 10.7$ & $37.0 \pm 12.5$ & 0.33 \\
\hline SAS $(\geq 50)^{\mathrm{a}}$ & $19(18.4 \%)$ & $8(6.6 \%)$ & $<0.01$ \\
\hline $\operatorname{SDS}(\geq 53)^{\mathrm{a}}$ & $38(36.9 \%)$ & $16(13.2 \%)$ & $<0.01$ \\
\hline BASDAl $^{\mathrm{b}}$ & $2.9 \pm 2.4$ & & \\
\hline BASFI ${ }^{b}$ & $0.9 \pm 1.5$ & & \\
\hline BASMI $^{b}$ & $2.4 \pm 1.8$ & & \\
\hline $\mathrm{HAQ}^{\mathrm{b}}$ & $2.8 \pm 2.2$ & & \\
\hline VAS pain ${ }^{\mathrm{b}}$ & $2.2 \pm 4.1$ & & \\
\hline Abnormal ESR & $24(23.3 \%)$ & & \\
\hline \multicolumn{4}{|l|}{ ( $\geq 15 \mathrm{~mm} / \mathrm{h}$ for men, $\geq 20 \mathrm{~mm} / \mathrm{h}$ for women) } \\
\hline Abnormal CRP $(\geq 8 \mathrm{mg} / \mathrm{L})^{\mathrm{a}}$ & $4 \mathrm{l}(39.8 \%)$ & & \\
\hline
\end{tabular}

Notes: aNumber (percentage), analyzed using the chi-square test; 'Mean (SD), analyzed using the Student's $t$-test.

Abbreviations: AS, ankylosing spondylitis; BASDAI, Bath Ankylosing Spondylitis Disease Activity Index; BASFI, Bath Ankylosing Spondylitis Functional Index; BASMI, Bath Ankylosing Spondylitis Metrology Index; CRP, C-reactive protein; ESR, erythrocyte sedimentation rate; h, hour; HAQ, Health Assessment Questionnaire for Spondyloarthropathies; SAS, revised Self-Rating Anxiety Scale; SD, standard deviation; SDS, revised Self-Rating Depression Scale; VAS, visual analog scale. 
Table 2 Pearson's correlation among psychological scores, disease parameters, and QoL in patients with AS

\begin{tabular}{|c|c|c|c|c|}
\hline \multirow[t]{2}{*}{ Variables } & \multicolumn{2}{|l|}{ SAS } & \multicolumn{2}{|l|}{ SDS } \\
\hline & $\boldsymbol{R}$ & $P$-value & $\boldsymbol{R}$ & $P$-value \\
\hline BASDAI & 0.48 & $<0.01$ & 0.43 & $<0.01$ \\
\hline BASFI & 0.21 & 0.13 & 0.18 & 0.20 \\
\hline BASMI & 0.27 & 0.06 & 0.15 & 0.32 \\
\hline VAS pain & 0.60 & $<0.01$ & 0.51 & $<0.01$ \\
\hline HAQ & 0.36 & $<0.01$ & 0.23 & 0.10 \\
\hline ESR & -0.04 & 0.80 & 0.13 & 0.37 \\
\hline CRP & 0.15 & 0.29 & 0.18 & 0.21 \\
\hline \multicolumn{5}{|l|}{ SF-36 domains } \\
\hline PCS & -0.46 & $<0.01$ & -0.48 & $<0.01$ \\
\hline MCS & -0.39 & $<0.01$ & -0.56 & $<0.01$ \\
\hline Physical functioning & -0.37 & $<0.01$ & -0.42 & $<0.01$ \\
\hline $\begin{array}{l}\text { Role limitations due to } \\
\text { physical problems }\end{array}$ & -0.39 & $<0.01$ & -0.48 & $<0.01$ \\
\hline Body pain & -0.32 & $<0.01$ & -0.36 & $<0.01$ \\
\hline General health perception & -0.47 & $<0.01$ & -0.29 & 0.03 \\
\hline Vitality & -0.45 & $<0.01$ & -0.52 & $<0.01$ \\
\hline Social functioning & -0.15 & 0.29 & -0.39 & $<0.01$ \\
\hline $\begin{array}{l}\text { Role limitations due to } \\
\text { emotional problems }\end{array}$ & -0.40 & $<0.01$ & -0.48 & $<0.01$ \\
\hline Mental health & -0.31 & 0.02 & -0.39 & $<0.01$ \\
\hline
\end{tabular}

Abbreviations: AS, ankylosing spondylitis; BASDAI, Bath Ankylosing Spondylitis Disease Activity Index; BASFI, Bath Ankylosing Spondylitis Functional Index; BASMI, Bath Ankylosing Spondylitis Metrology Index; CRP, C-reactive protein; ESR, erythrocyte sedimentation rate; $\mathrm{HAQ}$, Health Assessment Questionnaire for Spondyloarthropathies; MCS, mental components summary; PCS, physical components summary; QoL, quality of life; SAS, revised Self-Rating Anxiety Scale; SDS, revised Self-Rating Depression Scale; SF-36, short form 36; VAS, visual analog scale.

\section{Stepwise regression analysis for anxiety and depression}

Multiple stepwise linear regression analysis was performed to determine which variables were associated with anxiety and depression. All variables listed in Table 2 were selected except the summaries of the physical and mental components. The $P$-value for inclusion in the stepwise linear regression analysis was $\leq 0.05$. The anxiety and depression scores were entered as dependent variables, and the independent covariates included BASDAI, VAS pain, Health Assessment Questionnaire, and all SF-36 domains except SF. The initial analysis indicated no association between BASFI, BASMI, ESR, CRP levels and SAS or SDS scores. Only the significant variables were selected for multivariate analyses. Multivariate analyses indicated that general health perception was negatively associated with anxiety and that VAS pain and body pain were positively associated with anxiety (Table 4). Meanwhile, the VAS pain and energy/vitality scores were negatively and positively associated with depression, respectively (Table 4).

\section{Discussion}

This study strongly suggests that Chinese patients with AS are more likely to suffer from anxiety and depression when compared to healthy individuals. Psychological problems

Table 3 Disease status and QoL in the anxious and depressed subgroups

\begin{tabular}{|c|c|c|c|c|c|c|}
\hline \multirow[t]{2}{*}{ Variables } & \multicolumn{3}{|l|}{ SAS } & \multicolumn{3}{|l|}{ SDS } \\
\hline & $<\mathbf{5 0}$ & $\geq \mathbf{5 0}$ & $P$-value & $<53$ & $\geq 53$ & $P$-value \\
\hline BASDAI & $2.34 \pm 1.89$ & $5.32 \pm 2.97$ & 0.0001 & $1.89 \pm 1.70$ & $3.53 \pm 2.53$ & 0.01 \\
\hline BASFI & $0.88 \pm 1.46$ & $1.09 \pm 1.52$ & 0.58 & $0.36 \pm 0.89$ & $1.27 \pm 1.65$ & 0.02 \\
\hline BASMI & $2.37 \pm 1.80$ & $2.67 \pm 1.79$ & 0.51 & $1.95 \pm 1.77$ & $2.55 \pm 1.96$ & 0.06 \\
\hline VAS pain & $2.37 \pm 2.02$ & $4.4 \pm 2.05$ & 0.006 & $1.95 \pm 1.80$ & $3.24 \pm 2.24$ & 0.03 \\
\hline HAQ & $1.77 \pm 3.84$ & $4 \pm 5.12$ & 0.13 & I. $14 \pm 3.38$ & $2.85 \pm 4.49$ & 0.14 \\
\hline ESR $(\mathrm{mm} / \mathrm{h})$ & $17.4 \pm 20.2$ & $20.1 \pm 18.7$ & 0.41 & $16.3 \pm 15.1$ & $19.7 \pm 17.6$ & 0.45 \\
\hline CRP (mg/L) & $12.3 \pm 9.7$ & $15 \pm 9.4$ & 0.22 & $12.3 \pm 8.3$ & $16.4 \pm 9.1$ & 0.07 \\
\hline \multicolumn{7}{|l|}{ SF-36 domains } \\
\hline PCS & $2.7 I \pm 0.75$ & $2.49 \pm 0.63$ & 0.24 & $3.03 \pm 0.69$ & $2.39 \pm 0.67$ & 0.001 \\
\hline MCS & $2.42 \pm 0.67$ & $2.19 \pm 0.37$ & 0.18 & $2.78 \pm 0.50$ & $2.10 \pm 0.67$ & 0.0002 \\
\hline Physical functioning & $0.80 \pm 0.18$ & $0.7 I \pm 0.23$ & 0.14 & $0.85 \pm 0.16$ & $0.75 \pm 0.20$ & 0.05 \\
\hline Role limitations due to physical problems & $0.62 \pm 0.4 I$ & $0.45 \pm 0.37$ & 0.23 & $0.83 \pm 0.33$ & $0.43 \pm 0.37$ & 0.0002 \\
\hline Body pain & $0.72 \pm 0.19$ & $0.69 \pm 0.12$ & 0.51 & $0.75 \pm 0.20$ & $0.69 \pm 0.16$ & 0.23 \\
\hline General health perception & $0.57 \pm 0.17$ & $0.49 \pm 0.12$ & 0.15 & $0.60 \pm 0.20$ & $0.52 \pm 0.13$ & 0.11 \\
\hline Vitality & $0.7 I \pm 0.75$ & $0.65 \pm 0.08$ & 0.24 & $0.79 \pm 0.11$ & $0.64 \pm 0.14$ & 0.0001 \\
\hline Social functioning & $0.32 \pm 0.17$ & $0.29 \pm 0.18$ & 0.45 & $0.35 \pm 0.19$ & $0.29 \pm 0.16$ & 0.19 \\
\hline Role limitations due to emotional problems & $0.70 \pm 0.37$ & $0.53 \pm 0.45$ & 0.23 & $0.87 \pm 0.25$ & $0.54 \pm 0.40$ & 0.001 \\
\hline Mental health & $0.70 \pm 0.15$ & $0.63 \pm 0.16$ & 0.21 & $0.77 \pm 0.11$ & $0.64 \pm 0.15$ & 0.002 \\
\hline
\end{tabular}

Note: Results are presented as mean \pm SD and were analyzed using the Student's $t$-test.

Abbreviations: BASDAI, Bath Ankylosing Spondylitis Disease Activity Index; BASFI, Bath Ankylosing Spondylitis Functional Index; BASMI, Bath Ankylosing Spondylitis Metrology Index; CRP, C-reactive protein; ESR, erythrocyte sedimentation rate; HAQ, Health Assessment Questionnaire for Spondyloarthropathies; MCS, mental components summary; QoL, quality of life; SAS, revised Self-Rating Anxiety Scale; SDS, revised Self-Rating Depression Scale; SF-36, short form 36; SD, standard deviation; PCS, physical components summary; VAS, visual analog scale. 
Table 4 Stepwise regression analyses of medical and psychological variables and their relationship with anxiety/depression in patients with AS

\begin{tabular}{lllll}
\hline & Variables & Coefficient & $\mathbf{9 5 \%} \mathbf{C l}$ & $P$-value \\
\hline Anxiety & GH & -14.28 & $-25.99,-2.58$ & $0.0 \mathrm{I}$ \\
& VAS pain & 2.65 & $1.51,3.78$ & $<0.00 \mathrm{I}$ \\
& BP & 13.80 & $0.47,27.13$ & 0.04 \\
Depression & VAS pain & -27.32 & $-48.10,-6.54$ & $0.0 \mathrm{I}$ \\
& VT & 2.28 & $0.84,3.72$ & 0.003 \\
\hline
\end{tabular}

Abbreviations: AS, ankylosing spondylitis; $\mathrm{BP}$, body pain; $\mathrm{Cl}$, confidence interval; $\mathrm{GH}$, general health perception; VAS, visual analog scale; VT, energy/vitality.

were significantly associated with disease status and QoL; patients with AS and anxiety and depression had worse disease status, and patients with AS and depression had lower QoL. Among the assessed parameters, general health impairment and pain were associated with anxiety in patients with AS, while pain and vitality problems were associated with depression.

Notably, the results of this study strongly suggest that Chinese patients with AS differ from patients with AS from other countries. ${ }^{18}$ The prevalence of mental health disorders in People's Republic of China is roughly equivalent to the prevalence observed in other countries..$^{10}$ In this study, the depression and anxiety frequencies were $36.9 \%$ and $18.4 \%$, respectively. Cultural factors may influence mental disease diagnosis and management in People's Republic of China. ${ }^{19,20}$ Indeed, the observed rates of depression and anxiety in this study were $36.9 \%$ and $18.4 \%$, respectively, which are similar to a survey of Turkish patients with AS (39.8\% and 19.5\%, respectively). ${ }^{21}$ Although Baysal et al reported that Health Assessment Questionnaire scores were associated with anxiety and depression in Turkish patients with AS, they did not correlate with the SDS scores in our study population. ${ }^{21}$ Psychological problems were more prevalent in Moroccan patients with AS: $55.5 \%$ were depressed and $60 \%$ experienced anxiety. ${ }^{22}$ Another Moroccan study found a lower rate of depression than in our study and suggested that fatigue likely contributes to depression in patients with AS..$^{23,24}$

Laboratory data of disease severity were not associated with psychological parameters in American patients with AS. ${ }^{25}$ Similarly, in this study, there were no correlations between laboratory variables (ESR and CRP) and psychological problems (anxiety and depression). Martindale et al reported that the functional scores were associated with depression in patients with AS in the UK $;^{26}$ the mean disease activity and functional scores were worse in the subgroups with anxiety or depression, but the relationship between spine/hip mobility scores and psychological parameters was weak, which supports this study, but which is in contradiction with a recent report suggesting that spinal mobility and pain significantly correlate with SF-36 domains in Croatian patients with AS..$^{24}$ In addition, in our study, the three SF-36 subscales did not differ significantly between the depressed and nondepressed subgroups of patients with AS, but the underlying reason is unclear. A Spanish study that used different questionnaires showed that low disease activity was associated with better disease acceptance and reduced anxiety and depression. ${ }^{27}$

Cultural differences may be responsible for these discrepancies. In general, the Chinese individuals are reluctant to discuss their feelings outside of their family, ${ }^{11}$ which impedes diagnosis and treatment of depression, and may partly explain the low reported rate of depression in our study. Chinese families typically manage psychiatric conditions within the family for sometimes as long as 10-20 years. During this period, they will go through rejection and scapegoating processes. ${ }^{12}$ The Chinese cultural system emphasizes forbearance, endurance, humility, and harmony between people, ${ }^{10}$ which could explain the lack of a clear relationship among AS activity, SF impairment, and anxiety in our study.

Beside cultural factors, genetic factors may influence the results observed in patients with AS from different countries. $\mathrm{AS}$ is an autoimmune rheumatic disease. Although a number of different polymorphisms and mutations with variable penetrance were identified in the $H L A-B 27$ gene in different populations around the world, ${ }^{19,20}$ the $B * 2724$ genotype was exclusively reported in Chinese patients with $\mathrm{AS} .{ }^{28} \mathrm{~A}$ study has suggested that changes in the HLA family of genes are associated with affective disorders and depression. ${ }^{14}$ Thus, it is possible that AS evolution and management, as well as the psychological aspects of the disease (depression and anxiety), may be different in Chinese patients with AS when compared to that of patients from other countries and with different genotypes.

Most chronic diseases negatively affect QoL. ${ }^{24}$ The main symptoms reported by patients with AS are pain, stiffness, and physical restriction. ${ }^{27}$ Previous studies have shown that restricted spinal mobility due to chronic back pain influences psychological factors. ${ }^{10,29}$ This study strongly suggests that pain predicted psychological problems in Chinese patients with AS, which is supported by a previous study that reported a link between anxiety and depression and sleep disturbances in the same population. ${ }^{13}$ Unutzer et al reported that anxiety and depression observed in chronic diseases might also contribute to decreased QoL. ${ }^{30}$ With specific regard to patients with AS, Gordeev et al associated helplessness and poor 
health-related QoL in patients with AS. ${ }^{31}$ Previous studies have reported that impaired QoL and functional disability are independent risk factors for psychological disorders. ${ }^{13}$ In this study, all SF-36 domains were significantly associated with anxiety and depression, except SF impairment. Impairments in physical function, mental health, and associated limitations were also worse in depressed patients with AS. ${ }^{13}$

Taken together, the results of this study suggest that ethnic and cultural factors must be taken into consideration in health care guidelines for the management of AS, and particularly when applying international health care guidelines to Chinese patients with AS. There is a need to develop psychological guidelines of care that are specific to the Chinese people. Determining the correlation between psychological status and disease parameters should facilitate the development of treatment guidelines that should reduce the incidence or severity of depression and anxiety in Chinese patients with AS.

There are several limitations to this study. It was conducted in a small sample of patients with AS, but the number of subjects is similar to that reported by other studies. The measurements were limited to functional assessments and questionnaires, which were retrospective in nature. Since AS is more commonly diagnosed in men, there was an imbalance in sex distribution. Methodological issues could be responsible for the differences observed between countries, eg, the questionnaires, the patient/ physician relationship, the health care system per se, and/or medical insurance. The strengths of this study include a homogeneous study sample, the inclusion of a control group, and the use of several assessment tools and questionnaires.

\section{Conclusion}

In summary, disease activity is associated with psychological health in Chinese patients with AS, but this relationship is different when compared to that of patients with AS from other countries. Indeed, inherent characteristics of the Chinese society and different HLA polymorphisms and mutations resulted in a low frequency of reported depression as well as in a lack of association between AS activity and SF impairment and anxiety, compared to other countries. As in other populations, low socioeconomic status, lack of health insurance, and fatigue contributed to depression in Chinese patients with AS. These patients may require a psychological care approach that is different from the approaches applied in other countries.

\section{Acknowledgments}

This work was supported by the National Natural Science Foundation of China (Grant No 81172841), the Natural Science Foundation of Jiangsu Colleges and Universities
Grant (No 09KJB320010), the "Top Six Types of Talents" Financial Assistance of Jiangsu Province Grant (No 6), and the Jiangsu Province's Outstanding Medical Academic Leader Program (LJ201136). This work was also supported by the Science Foundation of Nantong City Grant (No HS2011054), the Beijing Medical Award Foundation (FSMYYSNT-001), the College Graduate Research and Innovation of Jiangsu Province (CXLX12_0891), the Nantong University Graduate Innovation Program (YKC12037), the Nantong Science and Technology Board (HS12966 and MS32015021), and the Bureau of Jiangsu Province (Z2010005). We want to thank Liren Li, Xinghang Zhu, Genkai Guo, Jie Qian, Haixia Cao, and Yunfei Xia for their assistance with this paper.

\section{Disclosure}

The authors report no conflicts of interest in this work.

\section{References}

1. Dickens C, McGowan L, Clark-Carter D, Creed F. Depression in rheumatoid arthritis: a systematic review of the literature with meta-analysis. Psychosom Med. 2002;64(1):52-60.

2. Ortancil O, Konuk N, May H, Sanli A, Ozturk D, Ankarali H. Psychological status and patient-assessed health instruments in ankylosing spondylitis. J Clin Rheumatol. 2010;16(7):313-316.

3. Younes M, Jalled A, Aydi Z, et al. Qualité de vie au cours de la spondylarthrite ankylsante. [Quality of life in ankylosing spondylitis]. Tunis Med. 2011;89(4):374-378. French.

4. Calin A, Garrett S, Whitelock H, et al. A new approach to defining functional ability in ankylosing spondylitis: the development of the Bath Ankylosing Spondylitis Functional Index. J Rheumatol. 1994;21(12): 2281-2285.

5. Garrett S, Jenkinson T, Kennedy LG, Whitelock H, Gaisford P, Calin A. A new approach to defining disease status in ankylosing spondylitis: the Bath Ankylosing Spondylitis Disease Activity Index.J Rheumatol. 1994;21(12):2286-2291.

6. Goie The HS, Steven MM, van der Linden SM, Cats A. Evaluation of diagnostic criteria for ankylosing spondylitis: a comparison of the Rome, New York and modified New York criteria in patients with a positive clinical history screening test for ankylosing spondylitis. Br J Rheumatol. 1985;24(3):242-249.

7. Daltroy LH, Larson MG, Roberts NW, Liang MH. A modification of the Health Assessment Questionnaire for the spondyloarthropathies. J Rheumatol. 1990;17(7):946-950.

8. Jenkinson TR, Mallorie PA, Whitelock HC, Kennedy LG, Garrett SL, Calin A. Defining spinal mobility in ankylosing spondylitis (AS). The Bath AS Metrology Index. J Rheumatol. 1994;21(9):1694-1698.

9. Zung WW. A rating instrument for anxiety disorders. Psychosomatics. 1971;12(6):371-379.

10. Lin K-M, Kleinman A, Lin T-Y. Overview of mental disorders in Chinese cultures: review of epidemiological and clinical studies. In: Kleinman A, Lin T-Y, editors. Normal and Abnormal Behavior in Chinese Culture. Berlin: Springer; 1981:237-272.

11. Lin TY. Psychiatry and Chinese culture. West J Med. 1983;139(6): 862-867.

12. Shek DT. Introduction: quality of life of Chinese people in a changing world. Soc Indic Res. 2010;95(3):357-361.

13. Li Y, Zhang S, Zhu J, Du X, Huang F. Sleep disturbances are associated with increased pain, disease activity, depression, and anxiety in ankylosing spondylitis: a case-control study. Arthritis Res Ther. 2012;14(5): R215. 
14. Stancer HC, Weitkamp LR, Persad E, et al. Confirmation of the relationship of HLA (chromosome 6) genes to depression and manic depression. II. The Ontario follow-up and analysis of 117 kindreds. Ann Hum Genet. 1988;52(pt 4):279-298.

15. Zhu TY, Tam LS, Lee VW, et al. Costs and quality of life of patients with ankylosing spondylitis in Hong Kong. Rheumatology (Oxford). 2008;47(9):1422-1425.

16. Zung WW. A self-rating depression scale. Arch Gen Psychiatry. 1965; 12:63-70.

17. Ware JE Jr, Sherbourne CD. The MOS 36-item short-form health survey (SF-36). I. Conceptual framework and item selection. Med Care. 1992;30(6):473-483.

18. Brown MA, Kennedy LG, MacGregor AJ, et al. Susceptibility to ankylosing spondylitis in twins: the role of genes, HLA, and the environment. Arthritis Rheum. 1997;40(10):1823-1828.

19. Brown MA. Genetics of ankylosing spondylitis. Curr Opin Rheumatol. 2010;22(2):126-132.

20. Sheehan NJ. HLA-B27: what's new? Rheumatology (Oxford). 2010; 49(4):621-631.

21. Baysal O, Durmus B, Ersoy Y, et al. Relationship between psychological status and disease activity and quality of life in ankylosing spondylitis. Rheumatol Int. 2011;31(6):795-800.

22. Hakkou J, Rostom S, Aissaoui N, et al. Psychological status in Moroccan patients with ankylosing spondylitis and its relationships with disease parameters and quality of life. J Clin Rheumatol. 2011;17(8): 424-428.

23. Aissaoui N, Rostom S, Hakkou J, et al. Fatigue in patients with ankylosing spondylitis: prevalence and relationships with disease-specific variables, psychological status, and sleep disturbance. Rheumatol Int. 2012;32(7):2117-2124.
24. Jajic Z, Rajnpreht I, Kovacic N, et al. Which clinical variables have the most significant correlation with quality of life evaluated by SF-36 survey in Croatian cohort of patient with ankylosing spondylitis and psoriatic arthritis? Rheumatol Int. 2012;32(11):3471-3479.

25. Brionez TF, Assassi S, Reveille JD, et al. Psychological correlates of self-reported functional limitation in patients with ankylosing spondylitis. Arthritis Res Ther. 2009;11(6):R182.

26. Martindale J, Smith J, Sutton CJ, Grennan D, Goodacre L, Goodacre JA. Disease and psychological status in ankylosing spondylitis. Rheumatology (Oxford). 2006;45(10):1288-1293.

27. Rodriguez-Lozano C, Gantes MA, Gonzalez B, et al. Patient-acceptable symptom state as an outcome measure in the daily care of patients with ankylosing spondylitis. J Rheumatol. 2012;39(7):1424-1432.

28. Ma HJ, Hu FP. Diversity of human leukocyte antigen-B27 alleles in Han population of Hunan province, southern China. Tissue Antigens. 2006;68(2):163-166.

29. Holmgren A, Wise M, Bouckons A. Pain management. In: Wise M, Rundell R, editors. Textbook of Consultation-Liaison Psychiatry. Washington, DC: American Psychiatric; 2002:989-1013.

30. Unutzer J, Patrick DL, Diehr P, Simon G, Grembowski D, Katon W. Quality adjusted life years in older adults with depressive symptoms and chronic medical disorders. Int Psychogeriatr. 2000;12(1):15-33.

31. Gordeev VS, Maksymowych WP, Evers SM, Ament A, Schachna L, Boonen A. Role of contextual factors in health-related quality of life in ankylosing spondylitis. Ann Rheum Dis. 2010;69(1):108-112.
Patient Preference and Adherence

\section{Publish your work in this journal}

Patient Preference and Adherence is an international, peer-reviewed, open access journal that focuses on the growing importance of patient preference and adherence throughout the therapeutic continuum. Patient satisfaction, acceptability, quality of life, compliance, persistence and their role in developing new therapeutic modalities and compounds to optimize

\section{Dovepress}

clinical outcomes for existing disease states are major areas of interest for the journal. This journal has been accepted for indexing on PubMed Central. The manuscript management system is completely online and includes a very quick and fair peer-review system, which is all easy to use. Visit http://www. dovepress.com/testimonials.php to read real quotes from published authors. 